University of Louisville

ThinkIR: The University of Louisville's Institutional Repository

Faculty Scholarship

2016

\title{
Communicating entrepreneurial passion: Personal passion vs. perceived passion in venture pitches
}

\author{
Kristen Lucas \\ University of Louisville, kristen.lucas@louisville.edu \\ Sharon Kerrick \\ Bellarmine University \\ Jenna Haugen \\ University of Louisville \\ Cole J. Crider \\ University of Louisville
}

Follow this and additional works at: https://ir.library.louisville.edu/faculty

Part of the Business and Corporate Communications Commons, Entrepreneurial and Small Business Operations Commons, and the Speech and Rhetorical Studies Commons

Original Publication Information

Lucas, K., Kerrick, S. A., \& Haugen, J., \& Crider, C. J. "Communicating Entrepreneurial Passion: Personal Passion vs. Perceived Passion in Venture Pitches." 2016. IEEE Transactions on Professional

Communication, 59(4): 363-378.

This Article is brought to you for free and open access by ThinkIR: The University of Louisville's Institutional Repository. It has been accepted for inclusion in Faculty Scholarship by an authorized administrator of ThinkIR: The University of Louisville's Institutional Repository. For more information, please contact thinkir@louisville.edu. 


\section{COMMUNICATING ENTREPRENEURIAL PASSION: \\ PERSONAL PASSION VS. PERCEIVED PASSION IN VENTURE PITCHES}

Kristen Lucas, University of Louisville Sharon Kerrick, Bellarmine University Jenna Haugen, University of Louisville Cole J. Crider, University of Louisville

\section{ABSTRACT}

Research problem: Entrepreneurial passion has been shown to play an important role in venture success and therefore in investors' funding decisions. However, it is unknown whether the passion entrepreneurs personally feel or experience can be accurately assessed by investors during a venture pitch. Research questions: (1) To what extent does entrepreneurs' personal passion align with investors' perceived passion? (2) To what cues do investors attend when assessing entrepreneurs' passion? Literature review: Integrating theory and research in entrepreneurship communication and entrepreneurial passion within the context of venture pitching, we explain that during venture pitches, investors make judgments about entrepreneurs' passion that have consequences for their investment decisions. However, they can attend to only those cues that entrepreneurs outwardly display. As a result, they may not be assessing the passion entrepreneurs personally feel or experience. Methodology: We used a sequential explanatory mixed methods research design. For our data collection, we surveyed 40 student entrepreneurs, video-recorded their venture pitches, and facilitated focus groups with 16 investors who viewed the videos and ranked, rated, and discussed their perceptions of entrepreneurs' passion. We conducted statistical analyses to assess the extent to which entrepreneurs' personal passion and investors' perceived passion aligned. We then performed an inductive analysis of critical cases to identify specific cues that investors attributed to passion or lack thereof. Results and conclusions: We revealed that there was a large misalignment between entrepreneurs' personal passion and investors' perceived passion. Our critical case analysis revealed that entrepreneurs' weak or strong presentation skills led investors either to underestimate or overestimate, respectively, perceptions of entrepreneurs' passion. We suggest that entrepreneurs should develop specific presentation skills and rhetorical strategies for displaying their passion, yet at the same time, investors should be wary of attending too closely to presentation skills when assessing passion.

Keywords: Communication effectiveness, oral communication, public speaking

\section{INTRODUCTION}

The venture pitch is a vitally important professional communication interaction for entrepreneurs and investors alike. In the venture pitch, entrepreneurs make a persuasive appeal to prospective investors with the goal of securing capital to build or grow their venture. At the same time, investors critically attend to the details of the pitch to determine whether the venture is worthy of funding-including considerations of both the business opportunity and the quality of the entrepreneur [1]-[4]. One key criterion used to evaluate entrepreneurs is passion, as it is considered to be a key predictor of future venture success. Recent research demonstrates that the ability of entrepreneurs to display passion may predict investors' perceptions of their passion, which may, in turn, motivate positive funding decisions [5]-[7]. Yet despite passion being a personally felt affective and cognitive experience [8], none of these studies have taken into consideration entrepreneurs' personal reports of their passion. Therefore, there have been calls to examine whether investors' assessments of entrepreneurs' passion are accurate [7] and to use recently developed measures of entrepreneurial passion in examining the relationship between personal, displayed, and perceived passion in the context of funding decisions [5].

This study seeks to answer these calls by posing two research questions:

RQ1 To what extent does entrepreneurs' personal passion align with investors' perceived passion?

RQ2 To what cues do investors attend when assessing entrepreneurs' passion? 
We answer these questions through the use of a sequential explanatory mixed methods study, including surveying student entrepreneurs regarding their passion, recording their venture pitch presentations, and conducting focus groups with investors to gauge their perceptions of entrepreneurs' passion. In the following sections, we first situate our study by presenting a literature review. Then we outline our methodology and present our findings. We close by describing our conclusions, limitations, and suggestions for future research.

\section{LITERATURE REVIEW}

The purpose of this section is twofold: First, we position the assessment of entrepreneurial passion as a communicative process of shared meaning-making between entrepreneurs and investors. Second, we demonstrate that despite passion's being a critical factor for entrepreneurial venture pitch success, we still don't know whether entrepreneurs and investors are indeed able to reach a shared understanding of entrepreneurs' passion. We begin this section by describing our theoretical orientation. Next, we position the venture pitch within the domain of professional entrepreneurship communication. From there, we integrate research and theory on entrepreneurial passion and the venture pitch. Finally, we conclude with the research questions that guide this study.

Theoretical Orientation We base this study on the broad theoretical foundation that communication is a process of shared meaning-making rather than one of simple transmission. Moreover, all messages carry multiple meanings: instrumental, what the communicator intends to accomplish; relational, an acknowledgement of or attempt to alter the relationship dynamics between sender and receiver; and identity, a self-presentation message about the values, competence, intentions, etc. of the sender [9], [10]. Clark and Delia explain that rhetorically competent communicators will set goals for each of these meanings and then strategically select signals, which are specifically adapted to the receiver, to convey those desired meanings [9]. Because passion is an attribute of entrepreneurs themselves, it is transmitted in the identity meaning of their messages. Of course, shared meaning is an imprecise process, and often a perfect match between what is intended and what is perceived cannot be achieved. Regardless of how careful the receiver is in setting goals and making communicative choices, the arbiter of those meanings is the receiver [10]. In other words, it is not what senders intend to communicate but what receivers perceive to be communicated that determines the meanings of the message.

To examine the process of shared meaning-making concerning entrepreneurs' passion in the context of venture pitches, we reviewed literature in two key conceptual areas: entrepreneurship communication and entrepreneurial passion. We centered our review of these bodies of literature on studies that intersect with venture pitches and/or investment decisions. We searched scholarly databases and entrepreneurship journals for terms such as pitch, presentation, business plan, communication, rhetoric, investors, venture capitalists, and business angels. We evaluated articles for inclusion based on relevancy to our research problem, the quality of journal in which it was published, its currency, and the number of times it was cited. We also carefully mined the reference lists of relevant articles to ensure that we exhausted our search.

Entrepreneurship Communication Communication-especially rhetorically competent communication-is vital for entrepreneurial success. In fact, communication is so essential to entrepreneurship that some argue entrepreneurship is constituted by communication [11]. Entrepreneurs spend the majority of their time engaged in a variety of communicative interactions for purposes of establishing and growing their ventures [12]. For instance, entrepreneurs write business plans that often serve as a make-or-break introduction to prospective investors [2], [13]; they perform cycles of reusing and refining content in presentation pitch decks as they sharpen their arguments for securing funding [14], [15]; they engage in storytelling about their venture to gain legitimacy in the eyes of potential investors [16]-[18]; they strategically use visual symbols (e.g., clothing, physical space, nonverbal cues) in natural interactions to project a professional image and control the scene for stakeholders in order to build credibility [19]; they rhetorically position their individual and organizational identities within publicly-available promotional materials [20], [21]; they symbolically signal their credentials and professionalism to help them acquire resources [22]; they communicate their entrepreneurial vision to align employees with goals and foster venture growth [23]; and they write numerous documents (e.g., letters, marketing collateral, product descriptions, service descriptions) to generate and sustain customer interest [24]. However, no other 
entrepreneurship communication genre has garnered more attention than the venture pitch.

The venture pitch is a communicative interaction in which entrepreneurs make a formal, oral persuasive appeal (often delivered with some sort of technical demonstration or slide show graphics) to potential investors with the goal of securing investment funding. In some cases, financial investment is immediate, as is the case with universitysponsored pitch competitions in which student-led teams compete for pre-determined award packages that may include money, services, convertible notes, etc. (e.g., Rice Business Plan Competition). Other times, the pitch serves a gatekeeping function, determining whether entrepreneurs will be invited to submit a written business plan, meet more formally with potential investors, and proceed to due diligence, as may be the case with investment clubs [25], [26].

Pitching has been positioned as the most important behavior in the opportunity exploitation stage of entrepreneurship because it serves as a signaling activity (sometimes the only signaling activity) by which entrepreneurs can establish the legitimacy of their ventures, and doing so is a necessary precursor to securing financial and reputational resources [11]. Because new firms do not yet have objective performance measures, during the pitch, entrepreneurs must send communicative signals that establish the likelihood of financial viability, such as providing information on the venture opportunity, the market, projected financial performance of the venture, and the entrepreneur's (or team's) ability to deliver.

The importance of communication skills for the success of venture pitching cannot be overstated. Pollack et al. maintained, "without a good pitch, resources will not likely be forthcoming" [11], and research supports their claim. Among the top criteria identified by investors when assessing venture pitches is whether entrepreneurs are "articulate in discussing the venture" [4]. Other studies show that presentation issues tend to dominate investors' initial reactions, with strong presentation skills increasing investors' overall interest in the venture [27] and weak skills overshadowing the business idea itself [1].

The specific rhetorical competencies needed for venture pitch success include vocal delivery (e.g., verbal fluency, vocal variety, vocal pitch, rate), facial expression (facial animation, facial expressiveness, eye contact), body language (proxemics, movement, posture, hand gestures), and content development (level and completeness of information, clarity of explanations, coherent or logical organization, sufficient evidence to support claims, high-quality slide graphics or technology demonstrations) [1], [6], [27], [28]. In an in-depth examination of successful and unsuccessful venture pitches, Galbraith et al. found that successful entrepreneurs spoke with greater pitch variety, made more hand gestures, stood closer to the investors during the pitch, used slides with more graphics than text, and clicked through slides more quickly [6].

While much attention is paid to how effective entrepreneurs are at meeting their instrumental goals of securing financial backing, one rhetorical competency that often gets overlooked is entrepreneurs' ability to communicate a preferred identity meaning. Yet research shows that when making decisions in conditions of high uncertainty, investors weigh their decisions heavily on their "gut feel" of intangible human capital traits-in other words, judgments of the entrepreneurs' identity [29]. In a study of investor decision-making regarding venture proposals, MacMillan et al. found that the character of entrepreneurs was the most cited criterion for positive investment decisions, concluding that the quality of the entrepreneur, and not the business idea itself, ultimately determined investors' funding decisions [4]. When it comes to specific elements of entrepreneurial identity desired by investors, one characteristic stands out from the rest: passion [3], [7], [27].

Entrepreneurial Passion and the Venture Pitch Because entrepreneurship is a high-risk, time-consuming, and resource-intensive activity, it is widely believed that to succeed, entrepreneurs must possess a deep passion that enables them to take initiative, put in the requisite hard work, overcome the inherent challenges, and survive the ups and downs of starting a new venture. Smilor poetically described entrepreneurial passion as "the determined, optimistic, and persistent desire to succeed at one's own venture. It is the 'fire in the belly' that makes the improbable possible" [30]. More recently, Cardon et al. provided a theoretically robust definition of entrepreneurial passion as "consciously accessible intense positive feeling experienced by engagement in entrepreneurial activities associated with roles that are meaningful and salient to the self-identity of the entrepreneur" [8], emphasizing its affective and cognitive nature. 
Despite being primarily an affective and cognitive phenomenon, passion can be a driver of behavior [31], which then influences entrepreneurial performance. Entrepreneurial passion has been theorized to lead to increases in creative problem solving, persistence, and absorption, which then contribute to increased entrepreneurial effectiveness in terms of opportunity recognition, venture creation, and venture growth [8]. Empirical research demonstrates that passion directly fuels entrepreneurial behavior. Entrepreneurs who are passionate have been shown to spend more hours engaged in entrepreneurial activity [31], set higher goals for venture growth [23], persist in the face of obstacles and setbacks [32], and inspire others to share a vision [33]. Behaviors such as these, in turn, contribute to subsequent venture growth [23].

Consequently, passion serves not as a gauge of the quality of a business idea itself, but instead as an indicator of the ability and drive of the entrepreneur to execute business ideas. Because of the connection between passion and entrepreneurial success, passion can be an important criterion for making investment decisions. In fact, the more experienced investors become, the more emphasis they put on entrepreneurs' passion [3], [7], suggesting that paying attention to passion is not a "rookie mistake," but a wise investing strategy.

However, a key concern of considering entrepreneurs' passion as part of the investment decision process is that passion is not directly observable. To explain, there are three levels of passion [5], [7].

- The first level of passion, personal passion, is passion that is personally felt or experienced by entrepreneurs. Aligned with Cardon et al.'s entrepreneurial passion [34], personal passion is affective and cognitive. As such, the "fire in the belly" of entrepreneurial passion is necessarily invisible.

- The second level of passion is displayed passion. This is the level where personal passion is outwardly expressed through a range of observable signals. Some signals may be intentionally chosen while others may be unintentional (e.g., when people speak more quickly when feeling excited or with a flatter pitch when they are bored).

- The third level of passion is perceived passion. This is the level where displays of passion (and other cues) are interpreted by others who arrive at an assessment of the entrepreneurs' passion.

As is to be expected, the process of translating personal passion to displayed passion to perceived passion is anything but perfect. Many opportunities exist for miscommunicating passion on both the side of entrepreneurs sending signals and investors receiving and interpreting signals.

The focus of research attention on entrepreneurial passion in the context of venture pitching has been on displayed and perceived passion, to the exclusion of personal passion [5, 7]. First and foremost, numerous studies demonstrate that investors are more likely to financially support entrepreneurs who are perceived as passionate [3]-[5], [35]. In an examination of four years of investor feedback on applications to an angel investment club, Mitteness et al. found that investors' perceived passion (i.e., investors concluding from presentations that "The CEO is passionate about the company" and "The CEO is very enthusiastic") positively influenced investment decisions [7].

Research also shows that perceived passion positively affects other kinds of investor assessments. Galbraith et al. conducted a study in which investors read and evaluated written business plans. Then they watched venture pitches and reevaluated the business plans. When investors perceived entrepreneurs as having a high degree of passion, their evaluations of the commercial potential of their respective ventures significantly increased, and conversely, when investors perceived entrepreneurs' as having a low degree of passion, investors' evaluations of commercial potential significantly decreased-even though in both cases, investors' evaluations of technical merit did not change [6].

In a study of pitching activity in the film industry, researchers found that perceptions of passion led to increased assessments of creative potential, but more importantly, it also increased passion among investors themselves [36]. As a corollary, entrepreneurs' apparent lack of passion can be a fatal flaw that dooms a proposal to certain failure and causes investors to "tune out" [1], [27], [36].

However, there are some mixed results regarding the relative importance of displayed passion. Notably, Chen et al. developed scales to measure the amount of affective passion (which they called "passion") and cognitive passion (which they called "preparedness") displayed by entrepreneurs during venture pitches [28]. Passion included a range of presentation skills that communicated 
enthusiasm, such as energetic body movements and animated facial expression; preparedness included qualities such as substantive content and logical development. Next, they examined the venture pitches made at a university's annual business plan competition. As part of the competition, the 55 investors who served as competition judges completed scales of displayed passion and displayed preparedness, and indicated their willingness to invest in the venture. The researchers revealed that displayed preparedness, not displayed passion or enthusiasm, significantly and positively impacted investment decisions.

Cardon et al. expanded on Chen et al.'s study by also examining displayed commitment (i.e., evidence of behavioral manifestations of passion, such as committing one's own money to the venture) and measuring investors' perceived passion [5]. They collected 60 video-recorded venture pitches made to a business angel investing group, in which investors had rated their perceptions of entrepreneurs' passion with a 2-item scale at the time of the pitch. Then the researchers coded the videos for three subtypes of displayed passion (i.e., enthusiasm, preparedness, commitment) and examined the influence of displayed passion on investors' perceptions of overall passion, as well as on their investment decisions. Displayed enthusiasm and displayed commitment (not displayed preparedness) predicted investors' perceived passion, which, in turn, positively influenced funding decisions.

Despite mixed results on displayed passion-or perhaps because of them-Mitteness et al. concluded, "regardless of the experienced [personal] passion or the displayed passion ... what matters to funding is perceived passion" [7]. Indeed, when it comes to financially backing a venture, perceived passion is the level of passion that counts the most - but only because investors believe that their perceptions of passion accurately reflect entrepreneurs' personal passion. However, because no study has yet compared entrepreneurs' personal passion to investors' perceived passion, it remains unknown whether there is any connection between the two.

There is an assumption that individuals who personally feel or experience passion for entrepreneurship will engage in communicative behaviors that accurately display their passion and that those displays in turn will be accurately assessed as perceived passion. Yet knowing that there are differences in entrepreneurs' rhetorical competence and presentation speaking skills, there is a distinct possibility that passionate entrepreneurs may not always send adequate cues of displayed passion and that entrepreneurs who are not passionate may send cues that are perceived as passion. Likewise, because of differences in social perception skills among investors, it is possible that displayed passion may go undetected, be dismissed, or otherwise be misread. Moreover, it is possible that the cues entrepreneurs send are not the same cues being attended to by investors when making assessments of passion. Therefore, we designed the current study to address this important gap in the research.

Research Questions The following research questions guide this study:

RQ1 To what extent does entrepreneurs' personal passion align with investors' perceived passion?

RQ2 To what cues do investors attend when assessing entrepreneurs' passion?

\section{METHODOLOGY}

In this section, we provide a rationale for our choice of research methodology. Then, we describe who participated in the study, how we collected our data, how we analyzed our data, and how we ensured the reliability and credibility of our data and analyses.

Choice of Research Methodology To conduct our study, we used a mixed methods design. Mixed methods research draws upon the strengths and compensates for the weaknesses of quantitative or qualitative research alone, provides more comprehensive evidence for examining research problems, and enables researchers to answer questions that they might otherwise be unable to address with a single approach [37]. Specifically, we employed a sequential explanatory research design. The sequential explanatory process refers to the ordering of analyses such that quantitative analysis is performed first to identify patterns, then qualitative analysis is performed to provide an explanation or interpretation of the quantitative findings [38].

Participants We sought participants who were aspiring entrepreneurs slated to compete in venture investment competitions. We recruited participants from three entrepreneurship programs based at a university in the midwestern United States. While participants were students, the stakes for 
the competitions were high and reflected true entrepreneurial investment opportunities.

The first program was a two-year entrepreneurship MBA program in the Business College. In this program, students formed new ventures - typically working with university technology transfer offices, but sometimes generating their own business ideas-to bring a high-tech product to market. Students in this program had completed six months of entrepreneurship coursework, formed their teams approximately three months prior to the study, and were delivering their first formal venture pitch as a team to a group of venture investors. Based on their performance, investors would determine whether teams would qualify to represent the Business College in a year-long circuit of venture investment competitions with significant prize monies that could provide seed funding for their businesses.

The second program was a global MBA program, in which European students spend a summer in the United States and enroll in a new venture development course sequence in the Business College. Like the MBA program, the global teams generate ideas from university technology transfer offices or develop their own ideas. The program culminates with a business plan competition, with awards of investment monies ranging between $\$ 10000$ to $\$ 20000$ to return the winning team to the United States for another national venture investment competition.

The third program is a 10-week entrepreneurship "boot camp" sponsored by the Engineering College. In this program, students get specialized training and mentoring on how to transform an idea-most typically a technology that they personally invented-into a product and business proposition that can attract investors. The boot camp program culminated in a venture pitch competition. The winner received a small cash prize of $\$ 1000$, a six-month membership at a local co-working space for tech start-ups, and information from investor-judges on additional targeted funding opportunities.

After receiving approval of our research project from the University's Institutional Review Board and from the directors of the three programs, we recruited participants via email and in-class visits. In total, we recruited 40 student entrepreneurs, including 11 from the entrepreneurship MBA program, 22 from the global MBA program, and 7 from the entrepreneurship boot camp. The majority of participants were male (87\%). Their average age was 29 (range 19-45), and they had an average of 7 years of professional work experience (range 0-20 years). In terms of previously completed education, their undergraduate degrees were in business (55\%), STEM disciplines (14\%), and other fields (31\%; e.g., psychology, communication). Additionally, we recruited experienced investors and entrepreneurs $(n=16)$ with extensive experience judging startup investment competitions to rate, rank, and evaluate the entrepreneurs. Because the focus was on the entrepreneurs and their passion, we did not collect any demographic information from the investors.

In the next three subsections, we detail the procedures we followed to collect our data. Because we employed a mixed methods design, we have organized this information by data collection phase. Within each subsection, we describe the instruments or qualitative data collection, then we provide details on our procedure for collection.

\section{How Self-Report Survey Data Were Collected from Entrepreneurs}

Instruments: As a first step, entrepreneurs completed a quantitative self-report of personal passion. This instrument included Cardon et al.'s 13-item entrepreneurial passion scale, which measures passion for the task-specific dimensions of founding, developing, and inventing [34]. It also included a 5-item scale of passion for entrepreneurial activity, which was adapted from Vallerand et al.'s dualistic model of passion (see Appendix I) and which has been demonstrated to be effective in assessing passion across a wide variety of activities [39], [40]. All items were rated on a 7-point Likert scale. Additionally, entrepreneurs reported basic demographic information.

Procedure. We administered hardcopies of the survey to entrepreneurs in their respective classes. Of the 49 students enrolled across the three programs, 40 completed the survey and voluntarily consented to having their pitches videorecorded for a participation rate of $82 \%$. We collected the completed surveys and assigned a unique participant ID code to each entrepreneur for analysis purposes. Then we entered the survey data into SPSS, a statistical analysis software program.

\section{How Venture Pitch Video Data Were Collected}

Qualitative Data Collection. As a second step, we collected qualitative data from the venture pitches themselves. Between 1 and 5 days after completing 
the self-report survey, entrepreneurs competed with their teams in their respective venture pitch competitions. We digitally video-recorded their pitches. The videos contained a wealth of potential qualitative data on entrepreneurs' displayed passion-including their physical appearance, presentation skills (e.g., vocal variety, eye contact), content of their presentation, etc. The videos served as the basis for investors to assess perceived passion.

Procedure. We edited the venture pitch videos to create an excerpt of each entrepreneur delivering his or her part of the pitch. We chose excerpts over complete venture pitches because we wanted to focus investors' attention on individual entrepreneurs. That is, showing an entire pitch could potentially divert attention away from the entrepreneur to the product being pitched or to other team members who may be more "noticeable." We trimmed the excerpts to two minutes for two reasons. First, previous research has established that 2-minute clips are sufficient for individuals to evaluate entrepreneurs' social skills and to be confident in those evaluations [41]. Second, 2-minute excerpts reduced the potential for respondent fatigue on the part of investors by shortening the total length of the focus group sessions. The clips included the first two minutes that each entrepreneur spoke in the presentation. To the greatest extent possible, we also digitally cropped the clips to show only the presenting entrepreneur (rather than. a wideshot of the entire team). We added a title screen to each video clip with the entrepreneur's first name and participant ID code. Finally, we transcribed each entrepreneur's excerpt.

\section{How Focus Group Assessment Data Were Collected from Investors}

Instrument. As a third step, experienced investors and venture pitch judges provided quantitative and qualitative data on their assessments of entrepreneurs' passion. The instruments included a 4-item scale that measured their perceptions of each entrepreneur's passion (see Appendix II) and a single item that measured investors' overall assessment of each entrepreneur (i.e., "With the right business idea, I would consider investing in this presenter"). The instrument also included a ranking sheet for force-ranking the entrepreneurs in order of perceived passion. Finally, we collected qualitative data from the investors by asking for open-ended feedback throughout the rating and ranking process.

Procedure. We collected investor evaluation data via a focus group approach. We used focus groups to encourage "sharing and comparing" between experts to gain deeper insights into their thinking process [42]. To begin, we pilot tested the instruments and focus group protocol with entrepreneurship doctoral students. Based on feedback and insights from the pilot test, we made slight adjustments to the procedural protocol (e.g., wording of questions to improve clarity). We randomly assigned each entrepreneur's venture pitch video clip to one of five focus group sessions, such that each focus group session included 8 entrepreneurs to rate and rank. Then, we recruited investors to participate in one of the five scheduled focus group sessions. Focus groups ranged in size from 2 to 4 investors.

The focus group sessions were facilitated by a researcher who had no previous interaction with the entrepreneurs or investors. The rating and ranking process required investors to watch the 2-minute clip of each entrepreneur. As they watched each clip, they completed the perceived passion scale and wrote open-ended comments. After each clip, the facilitator gave investors time to complete their rating sheets in an effort to reduce tendencies toward conformity and polarization that sometimes occur in focus group contexts [42].

After investors completed their written comments, the facilitator engaged them in a discussion of their perceptions of the entrepreneurs' passion. The following questions guided this inquiry:

- How much entrepreneurial passion does this entrepreneur have?

- What things did he or she say, do, etc. that led you to that conclusion?

After all eight entrepreneurs were evaluated, the facilitator asked investors to force-rank the entrepreneurs in descending order of perceived passion. After the investors completed their rankings, the facilitator solicited qualitative insights from the group by asking these follow-up questions:

- Of all the presenters you watched, which entrepreneur(s) demonstrated the most passion?

- Which one(s) demonstrated the least passion?

- To what extent would these entrepreneurs' passion (or lack thereof) sway your decision to invest? 
We recorded the focus group sessions, and a trained research assistant transcribed the sessions verbatim. Finally, we matched the investors' quantitative rating and ranking data to the entrepreneurs by participant ID number and entered those data into SPSS.

How Data Were Analyzed We began analysis by quantitatively comparing self-reports of personal passion against investor ratings and rankings of perceived passion. Next, we performed an inductive analysis of focus group transcripts and investors' written comments to identify cues that signaled passion or a lack thereof [43]. Finally, we identified critical cases that reflected the most significant patterns emerging from our quantitative analysis and returned to do a deeper analysis of those cases to offer additional insights and understanding [38].

Ensuring Reliability and Credibility We ensured reliability of our quantitative data by using scales of entrepreneurial passion that have been widely cited and demonstrated to be reliable [34], [40]. Further, we conducted reliability analyses of all our quantitative measures. All entrepreneurial passion scales revealed very strong internal reliabilities: entrepreneurial activity ( $\alpha=0.916)$, inventing ( $\alpha=0.932)$, founding $(\alpha=0.939)$, developing $(\alpha=0.843)$, and the combined passion measure $(\alpha=0.968)$.

Previous research has used specific scales for measuring passion in venture pitches [28]. However, these scales were deemed by communication experts to be too leading in terms of priming investors to look for specific presentation skills (e.g., "energetic body movements," "animated facial expression"). Therefore, we generated more broadly construed items of perceived entrepreneurial passion, similar to those used in previous research [7]. The 4-item perceived passion scale had a strong internal reliability $(\alpha=0.942)$.

Finally, in terms of our qualitative data analysis, we took several steps to ensure credibility of the findings, that is, the dependability and trustworthiness of the data and analysis [43]. First, three members of the research team individually performed open coding of the transcripts so that multiple researchers were deeply familiar with the data and could participate meaningfully in interrogation of the findings. The coders independently identified patterns in the data, confirmed key findings through discussion of common insights, and resolved limited discrepancies. Second, we used qualitative data coding software (Atlas.ti) to improve our ability to code and retrieve data, as well as to enable systematic exploration of relationships between codes [44]. Finally, we triangulated our analysis with data from multiple sources (written and oral comments) and used thick description to present our findings (i.e., "showing" our data instead of "telling" our interpretation) [45].

\section{FINDINGS}

Our study has revealed that in the context of venture pitches, there tends to be a large misalignment between entrepreneurs' personal passion and investors' perceived passion, which can be attributed in large part to speaking ability. This section starts by outlining our quantitative findings that document the extent of the misalignment between personal passion and perceived passion. Then we report the findings of our explanatory qualitative analysis that suggest that speaking ability is the main reason for investors' under- and overestimation of passion.

Misalignment between Personal Passion and Perceived Passion The first research question we asked was, to what extent does entrepreneurs' personal passion align with investors' perceived passion? To address this question, we conducted statistical tests to compare entrepreneurs' self-reported personal passion with investor-rated perceived passion. If entrepreneurs and investors are able to reach a shared understanding of passion, then the most personally passionate entrepreneurs will be perceived by investors to be the most passionate. As a first step, we calculated entrepreneurs' self-report of personal passion for each of the passion subscales. Perhaps unsurprisingly, entrepreneurs tended to rate themselves fairly high in terms of personal passion (means of various subscales ranged from 5.14-5.81 on a 7-point scale). Given high correlation of the subscales, we combined the items into a single measure of personal passion ( $M=5.45)$. See Table 1 for means, standard deviations, alphas, and correlations. To facilitate further analysis, we standardized the combined personal passion measure by converting it to a z-score.

As a next step, we calculated the investor-rated perceived passion for each entrepreneur. We standardized each investor's rating scores individually to account for their different anchor points (i.e., their tendency to rate harshly or generously). We then calculated the mean of the 4 -item perceived passion scale into a single item. Next, we standardized each investor's ranking (1-8) 
individually and reversed the sign, as higher ranking scores indicate a less favorable ("lower") evaluation. To weight the rating and ranking equally, we used the mean of the two standardized scores as a single item of investors' perceived passion. As a final data transformation, we created four additional variables reflecting detailed and broad rankings. First, we rank-ordered entrepreneurs' personal passion standardized scores from 1 to 40 , and then investors' perceived passion standardized scores from 1 to 40 . This step provided a detailed rank ordering. Then, because we recognized that differences in personal passion were not evenly spaced throughout the ranking-and especially that small differences between entrepreneurs who were next to each other on the rank ordering may be difficult to detect-we created variables that reflected a more general evaluation of relative passion. Based on zscores, we created "passion grade" variables that coded entrepreneurs' personal passion and investors' perceived passion on a 5-point scale. As cutoff points, z-scores $>0.75$ were coded 5 (very high), 0.4-0.74 were coded 4 (high), 0.4-0.4 were coded 3 (average), $-0.4--0.75$ were coded 2 (low), and $<-0.75$ were coded 1 (very low). This step provided a broader 5 -step ranking (vs. 40-step ranking) for purposes of testing whether investors were able to differentiate more generally between entrepreneurs' relative passion.

Table 1

Means, Standard Deviations, Alphas, and Correlations of Entrepreneurial Passion Scales

\begin{tabular}{|c|c|c|c|c|c|c|c|c|}
\hline & Mean & $S D$ & $\alpha$ & 1 & 2 & 3 & 4 & 5 \\
\hline 1. Entrepreneurial Activity & 5.14 & 1.16 & 0.916 & - & & & & \\
\hline 2. Inventing & 5.81 & 1.17 & 0.932 & 0.772 & - & & & \\
\hline 3. Founding & 5.44 & 1.41 & 0.939 & 0.841 & 0.817 & - & & \\
\hline 4. Developing & 5.39 & 1.11 & 0.843 & 0.764 & 0.755 & 0.789 & - & \\
\hline 5. Combined & 5.45 & 1.11 & 0.968 & 0.924 & 0.916 & 0.942 & 0.888 & - \\
\hline
\end{tabular}

With the scores standardized and ranked, we tested the extent to which entrepreneurs' personal passion was aligned with investors' perceived passion. We calculated a Spearman's rho, which is a rank order correlation. The test revealed a low $(\rho=0.256)$ and insignificant $(p=0.111)$ correlation among detailed rankings, suggesting that investors were unable to differentiate between the entrepreneurs who reported the most and least personal passion. We repeated the test with the respective passion grades which should have been easier for investors to gauge. Again there was a mismatch between entrepreneurs' and investors' passion grades $(\rho=0.273, p=0.088)$, which indicated investors were largely unable to sort entrepreneurs into broad rankings of high passion to low passion.

A closer examination of the data revealed that self-reports of personal passion and investor-ratings of perceived passion were usually quite discrepant. While entrepreneurs' and investors' assessments of personal and perceived passion matched in $25 \%$ of the cases, the average difference between the two was 0.69 standard deviations.

Additionally, nearly half the cases $(n=19)$ were off by two or more passion grades and, of those, a few $(n=3)$ were off by three or more. Given that differences were both positive and negative, these data indicate that, by and large, entrepreneurs and investors were unable to reach shared meaning regarding entrepreneurial passion during the venture pitch. Many entrepreneurs who reported being passionate were not successful in communicating an identity message that presented themselves as passionate; conversely, other entrepreneurs who were not particularly passionate were able to convey an identity message of passion.

Investors' Under- and Overestimation of Passion Because receivers are the ultimate arbiters of message meanings, it is important to gain a more complete understanding of the process by which investors assess entrepreneurial passion. Therefore, the second research question we asked was "To what cues do investors attend when assessing entrepreneurs' passion?" To answer this question, we performed a qualitative analysis of investors' focus group feedback. Specifically, because we used a sequential explanatory design, we engaged in an inductive analysis of critical cases.

To do so, we identified entrepreneurs who had the largest discrepancy between personal passion and perceived passion. The criteria included a ranking discrepancy of 20 positions and a passion grade discrepancy of at least 2 grades. The cases that fit 
these criteria included five entrepreneurs who reported high personal passion and were rated with low perceived passion (High-Low Cluster) and four entrepreneurs who reported low personal passion and were rated with mediumto-high perceived passion (Low-High Cluster).

Our results revealed that the strongest indicators of entrepreneurial passion were presentation skills and rhetorical competence. For the High-Low Cluster entrepreneurs, poor skills led to an underestimation of their passion; for the Low-High Cluster entrepreneurs, their strong skills led to an overestimation of perceived passion. The specific cues contributing to investors' under- and overestimation were confident body language, vocal variety, personal engagement with the investor, and verbal statements of passion.

Confident body language: The first cue that led to over- or underestimation of passion was confident body language. An investor described an entrepreneur in the Low-High cluster enthusiastically: "Even his face there, he's got his shoulders back, he has a confident look on his face, he seems happy about talking about his idea. That kind of demeanor throughout made me think he was passionate." Positive body language also reinforced investment confidence. When asked if they might invest in the entrepreneur, an investor noted, "I would. Probably not in this idea, but with the right idea. I liked his attitude and how he presents himself on the stage."

In contrast, timid body language was detrimental to assessments of entrepreneurs' passion in the High-Low cluster. One entrepreneur was critiqued for "lack stage presence" and for "seeming a little nervous." Another was critiqued for putting "his hands in his pockets." The investor interpreted this one simple gesture as "hiding a little bit from the audience." The investor explained, "I don't know if that is directly involved with passion, but I didn't view that as positive."

Vocal variety. The second cue that led to over- or underestimation of passion was vocal variety, including inflection, word emphasis, word pronunciation, and pauses between major thoughts. An entrepreneur in the Low-High cluster who used vocal variety in his pitch was assessed favorably by investors. One investor explained, "He took his time, steady pace, he tried to enunciate." Another described why taking time was viewed positively:

In a presentation, when you pause between major thoughts, you're confident in what you presented. It's not like, 'Oh I memorized these 2 minutes and I got to get it out in 1:59.' This is about conveying the idea so that confidence is also part of passion. That comes through in the delivery.

In the High-Low cluster, investors attributed a lack of vocal variety as a telltale sign of the absence of passion. One investor remarked after a pitch, "Yeah. I think he completely lacks passion. He just doesn't seem excited about the venture at all." Another investor in the group added, "There's no animation. There's no inflection in his voice. I don't even think he introduced himself." Though investors expressed a desire for vocal animation, they did not necessarily expect entrepreneurs to be exceptionally dynamic, but they did expect them to be at least somewhat lively. One investor noted the importance of variety when he said, "I think low key pitches can be really good sometimes, but I thought it was too flat, tired, and kind of lacked emotion." Another investor noted about one entrepreneur struggling to display passion, "He was very monotone and wasn't very charismatic to me at all." Perhaps most bluntly of all, an investor remarked, "he bored me to death."

Personal engagement with the investor: The third cue that led to over- or underestimation of passion was entrepreneurs' ability to send signals of personal engagement with investors. Some of these signals included "interacting with the crowd through eye contact," "gestures," and presenting with a "conversational" style or tone. One investor, discussing a particularly strong presentation by an entrepreneur in the Low-High cluster, described his rationale for rating the entrepreneur highly: “I think general style points. You don't have notes. You're standing in front of the group. That helps with delivery for sure." Another investor mentioned the importance of the conversational approach. In describing why she rated an entrepreneur as the most passionate of the group she said, "I felt like when he was talking, he was talking to me and we were just having a conversation."

In contrast to an engaged style, several entrepreneurs "lacked enthusiasm," appeared to be reciting memorized scripts, or otherwise seemed "disengaged" from the investors. One investor who noted that an entrepreneur "lacked a lot of enthusiasm" explained his reasoning: "You're sitting there reading off a paper, you're looking up at the screen, reading off of the screen. I mean 
those are just $100 \%$ things that are a no-no that you learn in undergrad." The appearance of a scripted presentation and lack of an extemporaneous speaking style also were presumed to be evidence of little passion:

You can tell that he practiced, but he ... you know how when you're passionate, you'll have a bullet point, and you'll expand on that. I thought he ... kind of memorized his whole talk. Bottom line is that I probably wouldn't give this guy money.

Another investor disapproved of an entrepreneur's lack of engagement during Q\&A and noted:

He was answering questions from the crowd, and there wasn't any interaction. There was no "oh look what we can do with that," "great questions," or "here's how we've addressed that." He was very focused on pushing the buttons and showing what it can do, but that didn't convey any passion to me.

Moreover, a lack of engagement with the investors could lead them to underestimate entrepreneurs' passion, even when presented with evidence of other kinds of specific behaviors that could indicate passion or commitment. For instance, one entrepreneur who was pitching a technology he invented was met with mixed signals. After one investor acknowledged that it "seemed like he was the one that went to school and studied technology," the other continued:

He was trustworthy as an engineer. He was talking about the [specifics of the technology], and I totally believe that he invented something like that. It probably works really well, but somehow he still didn't seem passionate, even if he did invent the thing. He didn't seem super into it somehow.

Statements of passion: The final cue that led to over- or underestimation of passion was explicit statements of passion. Investors paid close attention to the rhetorical choices entrepreneurs made as they presented their ideas.

Entrepreneurs rated with high perceived passion tended to use personal narratives, positive words (e.g., "excited," "great," "tremendous," "stoked"), and confident language (e.g., "when we" instead of "if we") in their pitches. Below we describe two entrepreneurs who had similar self-reported personal passion, but were perceived very differently by investors. The first was overestimated by two passion grades and an overall ranking boost of 20 spots (from 25 to 5); the second was underestimated by two passion grades and an overall ranking drop of 22 spots (from 18 to 40).

In the case of the former, the entrepreneur drew upon language choices to display passion as he introduced his venture team:

These guys here around me, they are experts in their fields. But what we share most in common is our passion. And we will endure. And we already discussed this, it doesn't matter what we get here for grades, we want to start up this business. We want to go for it.

His language choices-including the word "passion" - were not lost on investors. Even though the entrepreneur reported below average personal passion, one investor described how he could tell the entrepreneur was passionate:

His mention of passion and just saying "we're doing this for us, and we don't care how we do in this presentation." I felt like that was confirmed too when he mentioned his team because he spoke really highly of them and his tone. I did believe - and I really do believe - that they are going to try to do this. I liked him and he seemed to know his stuff.

In the case of the latter entrepreneur, his rhetorical choices had the opposite effect. After a nearly 40 -second introduction of his faculty mentor, the entrepreneur finally introduced his business:

So, okay. So, uh. [pauses several seconds] So we, as you can see the name, we already got the domain [Company Name]. But we haven't yet, uh, incorporated the company. And we'll be doing that in the coming week. And, umm. So basically our company is going to have three divisions.

Investors did not respond favorably. Despite the entrepreneur reporting slightly above average personal passion, the investors were unable to perceive that passion and rated him as the least passionate entrepreneur overall. One investor said, "there's just no general level of excitement to start off." Another investor in the group added:

He wasn't excited about it; I didn't get excited about it. I don't have any idea what this product is about. So just the fact there's not a lot of knowledge coming my way as well as lack of excitement just makes you think there's 
not much interest.... When you have a business idea or venture there's going to be something, a reason for people to invest, and he didn't even point out what that was. You're initially left like "why are we even here?"

In summary, investors attended to a range of verbal and nonverbal signals that served as indicators about entrepreneurs' passion or lack thereof. In particular, investors perceived entrepreneurs with confident body language, vocal variety, personal engagement, and verbal statements of passion as having high passion. Likewise, the absence of these rhetorical features conveyed an identity meaning devoid of passion.

\section{CONCLUSIONS, LIMITATIONS, AND SUGGESTIONS FOR FUTURE RESEARCH}

In this study, we examined the extent to which entrepreneurs' reports of personal passion align with investors' perceptions of that passion and then engaged in further analysis to understand the cues that may impede the implicit goal of reaching shared meaning. In this concluding section we outline our conclusions, identify the limitations of the study, and make suggestions for future research.

Conclusions By positioning the venture pitch as a professional communication context in which entrepreneurs presumably display cues in an attempt to convey their passion to investors and in which investors attempt to decipher available cues to make an accurate assessment of the entrepreneurs' passion, we demonstrated that when it comes to passion, there was a misalignment between what entrepreneurs personally feel or experience and what investors perceive. Importantly, the misalignment occurred in both directions. That is, in addition to passionate entrepreneurs not always being able to convey their passion, entrepreneurs without much passion frequently were perceived by investors as having strong passion.

Moreover, by performing a deeper examination of critical cases in which the degree of misalignment between personal and perceived passion was large, we revealed that speaking skills-including confident body language, vocal variety, personal engagement with investors, and explicit statements of passion-were the key factor contributing to investors incorrectly estimating entrepreneurs' passion or lack thereof. Poor presentation skills diminished perceived passion, and strong presentation skills heightened perceived passion.

There are important implications from these findings. First, from a research standpoint, this study is the first to examine the relationship between entrepreneurs' personal passion [34], [40] and investors' perceived passion. Because we revealed that there is not close alignment between the two, there are important implications for interpreting previous research and conducting future research that establishes relationships between entrepreneurial passion and investment decision-making. Furthermore, this study provides empirical support that personal passion is distinct from displayed and perceived passion. Therefore, future research-particularly in the domain of entrepreneur-investor interactions-needs to be explicit about what kind of passion is being addressed.

From a practical standpoint, the findings from this study reveal important insights for entrepreneurs and investors alike when it comes to projecting and assessing passion. At the outset, it is important to emphasize that because the venture pitch is a communicative interaction and because communication is a two-way process of meaning-making, both entrepreneurs and investors contribute to the misalignment. In other words, it is not the case that one party is right and the other is wrong. Instead, entrepreneurs should be more conscientious in displaying their passion in strategic ways that are tailored to their receiver, but investors should also make more conscientious efforts to interpret all available cues when assessing passion.

For entrepreneurs, the foremost lesson is that presentation skills matter. Simply put, a lack of delivery skills is a liability to projecting passion - and that apparent lack of passion can be a deal-breaker for securing funding from investors. Therefore, in addition to developing the content of their presentation and being knowledgeable about their business, entrepreneurs should seek feedback and coaching on presentation skills, including body language, vocal enthusiasm, facial animation, and so forth.

Especially for those entrepreneurs who may struggle with nonverbal delivery skills or communication apprehension, the findings suggest that they may be able to compensate for stage presence by using more passionate language and making explicit rhetorical claims of passion. For instance, instead of saying, "Next I'll talk about financial projections," entrepreneurs may be able to project more passion by saying, "I'm excited to tell you about the financial projections." They also might make direct statements of their passion and provide evidence (e.g., "Because I spent six months 
developing this technology, I am very passionate about bringing the product to market").

Entrepreneurs may benefit from "passion priming" as a way of developing their rhetorical competence and venture pitch success. In addition to thinking about their instrumental goals of securing funding, entrepreneurs should identify explicit goals about the identity they intend to project in general and the passion that they intend to project in particular. Being more consciously aware of displaying passion may help entrepreneurs translate their personal passion into displayed passion, which will increase the likelihood of investors reaching favorable assessments of perceived passion. It might also give entrepreneurs an opportunity to practice different combinations of strategies to find the ones that are most consistent with their personal style.

For investors, the most important lesson is "buyer beware." Our findings suggest that the cues to which investors attend when assessing entrepreneurial passion may be more indicative of speaking ability than they are of passion. As such, investors may miss investment opportunities with passionate entrepreneurs who simply are struggling with presentation skills, or make less than optimal investments in entrepreneurs who are projecting a passionate image but do not have the "fire in the belly" to back their message up. This warning is not meant to dismiss the importance of entrepreneurs' presentation skills in their own right but instead to identify the risk associated with misattributing those skills to a different characteristic.

Therefore, assuming that investors still are motivated to invest in passionate entrepreneurs, they may be wise to include as part of their investment screening process questions that more directly address investor passion. For instance, they may ask entrepreneurs for evidence of their passion, such as willingness to overcome a setback or to take a personal risk for the sake of the venture, or they might ask entrepreneurs an open-ended question regarding what drives their passion for the venture. These kinds of queries could provide much greater insight and a stronger basis for evaluating passion.

Limitations There are some limitations to this study, with regard to the sampling and data collection. In regard to sampling, first, the data for this study came from student venture pitch competitions, a fact that raises concerns for generalizability. For instance, while these presentations were not simply "in-class" activities, the stakes were lower than they would be for more experienced entrepreneurs in advanced stages of venture funding.

Second, the investors who ranked and rated the entrepreneurs were not the same investors who made investment decisions during the competition. Therefore, the investors in the focus groups may not have been as committed to the assessment process as were the investors who participated in the live venture pitch competitions, or alternatively they may have been more attuned to passion cues because we were directing their attention specifically to passion.

Third, in regard to data collection procedures, we used short clips of entrepreneurs who were presenting as part of a team. While short clips have been demonstrated to be sufficient for assessing entrepreneurs on various social dimensions, an issue that arises is that the section of the pitch entrepreneurs personally covered may have affected overall judgments. For instance, some investors made excuses for lack of apparent passion when entrepreneurs covered the "less exciting" aspects of the venture (e.g., covering financials instead of product overview).

Fourth, there was a slight inconsistency in the scales used to measure passion. The personal passion scales measured passion for entrepreneurship broadly, while the perceived passion scale included items that were specific to perceptions of passion for a particular venture or pitch. These scales may obscure potentially important differences between general and context-specific passion.

Finally, we did not question entrepreneurs either before or after to assess to what extent they were consciously attempting to project passion.

Suggestions for Future Research Based on the limitations identified above, we have several suggestions for future research. Other researchers could attempt to replicate these findings with entrepreneurs and investors outside the scope of student competitions. By examining the alignment of personal and perceived passion with highly motivated entrepreneurs and investors, we should see stronger efforts by both parties to project and critically assess passion. Likewise, examining complete pitches made by individual entrepreneurs (instead of by a team) might provide additional insights 
as investors would be able to see whether passion ebbs and flows during various parts of the pitch.

We would especially like to see future studies that examine entrepreneurs' rhetorical strategies for projecting passion to investors. Research in this vein could include interviews or ethnographic studies of successful venture pitchers to understand their strategies. Other studies might examine the effects of presentation coaching or impression management coaching on perceptions of entrepreneurial passion and investment success. Finally, studies could examine the relatively effectiveness of nonverbal (presentation skills) and verbal (explicit statements of passion) cues on perceptions of passion.

\section{REFERENCES}

[1] C. M. Mason and R. T. Harrison, “'Auditioning for money': What do technology investors look for at the initial screening stage," J. Private Equity, vol. 6, no. 2, pp. 29-42, 2003.

[2] C. M. Mason and M. Stark, "What do investors look for in a business plan?: A comparison of the investment criteria of bankers, venture capitalists and business angels," Int. Small Bus. J., vol. 22, no. 3, pp. 227-248, 2004.

[3] R. Sudek, “Angel investment criteria,” J. Small Bus. Strat., vol. 17, no. 2, pp. 89-103, 2006.

[4] I. C. MacMillan, R. Siegel, and P. N. S. Narasimha, “Criteria used by venture capitalists to evaluate new venture proposals," J. Bus. Venturing, vol. 1, no. 1, pp. 119-128, 1985.

[5] M. S. Cardon, R. Sudek, and C. Mitteness, "The impact of perceived entrepreneurial passion on angel investing," Frontiers Entrep. Res., vol. 29, no. 2, pp. 1-13, 2009.

[6] C. S. Galbraith, B. C. McKinney, A. F. DeNoble, and S. B. Ehrlich, "The impact of presentation form, entrepreneurial passion, and perceived preparedness on obtaining grant funding," J. Bus. Tech. Commun., vol. 28, no. 2, pp. 222-248, 2014.

[7] C. Mitteness, R. Sudek, and M. S. Cardon, "Angel investor characteristics that determine whether perceived passion leads to higher evaluations of funding potential," J. Bus. Venturing, vol. 27, no. 5, pp. 592-606, 2012.

[8] M. S. Cardon, J. Wincent, J. Singh, and M. Drnovsek, "The nature and experience of entrepreneurial passion," Acad. Manage. Rev., vol. 34, no. 3, pp. 511-532, 2009.

[9] R. A. Clark and J. G. Delia, “Topoi and rhetorical competence," Q. J. Speech, vol. 65, no. 2, pp. 187-206, 1979.

[10] K. Lucas and J. D. Rawlins, "The competency pivot: Introducing a new approach to the business communication curriculum," Bus. Prof. Commun. Q., vol. 78, no. 4, pp. 167-193, 2015.

[11] J. M. Pollack, M. W. Rutherford, and B. G. Nagy, "Preparedness and cognitive legitimacy as antecedents of new venture funding in televised business pitches," Entrep. Theory Pract., vol. 36, no. 5, pp. 915-939, 2012.

[12] S. Mueller, T. Volery, and B. von Siemens, "What do entrepreneurs actually do? An observational study of entrepreneurs' everyday behavior in the start-up and growth stages," Entrep. Theory Pract., vol. 36, no. 5, pp. 995-1017, 2012.

[13] B. Mainprize and K. Hindle, "The benefit: A well-written entrepreneurial business plan is to an entrepreneur what a midwife is to an expecting mother," J. Private Equity, vol. 11, no. 1, pp. 40-52, 2007.

[14] C. Spinuzzi, S. Nelson, K. S. Thomson, F. Lorenzini, R. A. French, G. Pogue, et al., "Remaking the pitch: Reuse strategies in entrepreneurs' pitch decks," IEEE Trans. Prof. Commun., vol. 58, no. 1, pp. 45-68, 2015.

[15] C. Spinuzzi, S. Nelson, K. S. Thomson, F. Lorenzini, R. A. French, G. Pogue, et al., "Making the pitch: Examining dialogue and revisions in entrepreneurs' pitch decks," IEEE Trans. Prof. Commun., vol. 57, no. 3, pp. 158-181, 2014. 
[16] B. G. Nagy, J. M. Pollack, M. W. Rutherford, and F. T. Lohrke, “The influence of entrepreneurs' credentials and impression management behaviors on perceptions of new venture legitimacy," Entrep. Theory Pract., vol. 36, no. 5, pp. 941-965, 2012.

[17] E. O'Connor, "Storied business: Typology, intertextuality, and traffic in entrepreneurial narrative," J. Bus. Commun., vol. 39, no. 1, pp. 36-54, 2002.

[18] M. Lounsbury and M. A. Glynn, "Cultural entrepreneurship: Stories, legitimacy, and the acquisition of resources," Strategic Manage. J., vol. 22, no. 6-7, pp. 545-564, 2001.

[19] J. Clarke, "Revitalizing entrepreneurship: How visual symbols are used in entrepreneurial performances," J. Manage. Stud., vol. 48, no. 6, pp. 1365-1391, 2011.

[20] M. L. Martens, J. E. Jennings, and P. D. Jennings, "Do the stories they tell get them the money they need? The role of entrepreneurial narratives in resource acquisition," Acad. Manage. J., vol. 50, no. 5, pp. 1107-1132, 2007.

[21] D. Marom and O. Sade. (2014). "Are the life and death of a young start-up indeed in the power of the tongue? Lessons from online crowdfunding pitches," SSRN Electronic Journal. [Online]. Available: http://papers.ssrn.com/sol3/papers.cfm?abstract_id= 2255707

[22] C. Zott and Q. N. Huy, "How entrepreneurs use symbolic management to acquire resources," Admin. Sci. Quart., vol. 52, no. 1, pp. 70-105, 2007.

[23] J. R. Baum and E. A. Locke, "The relationship of entrepreneurial traits, skill, and motivation to subsequent venture growth," J. Appl. Psychol., vol. 89, no. 4, pp. 587-598, 2004.

[24] J. M. Spartz and R. P. Weber, "Writing entrepreneurs: A survey of attitudes, habits, skills, and genres," J. Bus. Tech. Commun., vol. 29, no. 4, pp. 428-455, 2015.

[25] J. May, "Structured angel groups in the USA: The Dinner Club experience," Venture Capital, vol. 4, no. 4, pp. 337-342, 2002.

[26] W. H. Payne and M. J. Macarty, "The anatomy of an angel investing network: Tech Coast Angels," Venture Capital, vol. 4, no. 4, pp. 331-336, 2002.

[27] C. Clark, "The impact of entrepreneurs' oral 'pitch' presentation skills on business angels' initial screening investment decisions," Venture Capital, vol. 10, no. 3, pp. 257-279, 2008.

[28] X.-P. Chen, X. I. N. Yao, and S. Kotha, "Entrepreneur passion and preparedness in business plan presentations: A persuasion analysis of venture capitalists' funding decisions," Acad. Manage. J., vol. 52, no. 1, pp. 199-214, 2009.

[29] L. Huang and J. L. Pearce, "Managing the unknowable: The effectiveness of early-stage investor gut feel in entrepreneurial investment decisions," Admin. Sci. Quart., vol. 60, no. 4, pp. 634-670, 2015.

[30] R. W. Smilor, "Entrepreneurship: Reflections on a subversive activity," J. Bus. Venturing, vol. 12, no. 5, pp. 341346, 1997.

[31] C. Y. Murnieks, E. Mosakowski, and M. S. Cardon, "Pathways of passion: Identity centrality, passion, and behavior among entrepreneurs," J. Manage., vol. 40, no. 6, pp. 1583-1606, 2014.

[32] M. S. Cardon and C. P. Kirk, "Entrepreneurial passion as mediator of the self-efficacy to persistence relationship," Entrep. Theory Pract., vol. 39, no. 5, pp. 1027-1050, 2015.

[33] M. S. Cardon, "Is passion contagious? The transference of entrepreneurial passion to employees," Hum. Resour. Manage. R., vol. 18, no. 2, pp. 77-86, 2008. 
[34] M. S. Cardon, D. A. Gregoire, C. E. Stevens, and P. C. Patel, "Measuring entrepreneurial passion: Conceptual foundations and scale validation," J. Bus. Venturing, vol. 28, no. 3, pp. 373-396, 2013.

[35] M. S. van Osnabrugge, "The financing of entrepreneurial firms in the UK: A comparison of business angel and venture capitalist investment procedures," PhD dissertation, Univ. Oxford, Oxford, UK, 1998.

[36] K. D. Elsbach and R. M. Kramer, "Assessing creativity in Hollywood pitch meetings: Evidence for a dualprocess model of creativity judgments," Acad. Manage. J., vol. 46, no. 3, pp. 283-301, 2003.

[37] J. W. Creswell and V. L. Plano Clark, Desiging and Conducting Mixed Methods Research. Thousand Oaks, CA: SAGE, 2007.

[38] J. W. Creswell, Qualitative Inquiry and Research Design: Choosing Among Five Approaches. 3rd ed. Thousand Oaks, CA: SAGE, 2013.

[39] H. W. Marsh, R. J. Vallerand, M. A. Lafreniere, P. Parker, A. J. Morin, N. Carbonneau, et al., "Passion: Does one scale fit all? Construct validity of two-factor passion scale and psychometric invariance over different activities and languages," Psychol. Assessment, vol. 25, no. 3, pp. 796-809, 2013.

[40] R. J. Vallerand, C. Blanchard, G. A. Mageau, R. Koestner, C. Ratelle, M. Léonard, et al., "Les passions de l'âme: On obsessive and harmonious passion," J. Personality Social Psych., vol. 85, no. 4, pp. 756-767, 2003.

[41] R. A. Baron and C. G. Brush, "The role of social skills in entrepreneurs' success: Evidence from videotapes of entrepreneurs' presentations," in Frontiers Entrep. Res., Babson Park, MA, 1999.

[42] D. L. Morgan, Focus Groups as Qualitative Research. 2nd ed. Thousand Oaks, CA: SAGE, 1997.

[43] S. J. Tracy, Qualitative Research Methods: Collecting Evidence, Crafting Analysis, Communicating Impact. Hoboken, NJ: Wiley-Blackwell, 2013.

[44] K. Lucas, "Computer-assisted qualitative data analysis software (CAQDAS)," in SAGE Encyclopedia of Communication Research Methods. M. Allen, Ed. Thousand Oaks, CA: SAGE, forthcoming.

[45] S. J. Tracy, "Qualitative quality: Eight "big-tent" criteria for excellent qualitative research," Qual. Inq., vol. 16, no. 10, pp. 837-851, 2010.

\section{APPENDIX I.}

PASSION FOR ENTREPRENEURIAL ACTIVITY SCALE ITEMS $(\alpha=0.916)$

I spend a lot of time doing entrepreneurial activities.

I like being an entrepreneur.

Being an entrepreneur is important for me.

Being an entrepreneur is a passion for me.

Being an entrepreneur is a part of who I am. 
APPENDIX II.

PERCEIVED PASSION SCALE ITEMS $(\alpha=0.942)$

The entrepreneur appeared to be genuinely passionate about the venture.

The entrepreneur communicated with passion during the pitch.

The entrepreneur was well prepared for the pitch.

The entrepreneur clearly articulated his/her passion for the venture.

\section{Full Citation:}

Lucas, K., Kerrick, S. A., \& Haugen, J., \& Crider, C. J. (2016). Communicating entrepreneurial passion: Personal passion vs. perceived passion in venture pitches. IEEE Transactions on Professional Communication, 59(4), 363-378. doi:10.1109/TPC.2016.2607818

Published Version Available: http://ieeexplore.ieee.org/abstract/document/7604127/ 